\title{
Biodegradable nanoparticles designed for drug delivery: The number of nanoparticles impacts on cytotoxicity
}

\author{
Lívia Palmerston Mendes ${ }^{\mathrm{a}}$, Jorge Miguel Ferreira Delgado ${ }^{\mathrm{b}}$, Angela Daniela A. Costa ${ }^{\mathrm{b}}$, \\ Marcelo Sousa Vieira ${ }^{\mathrm{c}}$, Poliana Lopes Benfica ${ }^{\mathrm{c}}$, Eliana Martins Lima ${ }^{\mathrm{a}, *}$, Marize Campos Valadares ${ }^{\mathrm{c}, *}$ \\ a Laboratory of Pharmaceutical Nanotechnology and Drug Delivery Systems, School of Pharmacy, Federal University of Goiás, Goiânia, Goiás, Brazil \\ ${ }^{\mathrm{b}}$ Escola Superior de Tecnologia e Gestão, Instituto Politécnico de Bragança, Bragança, Portugal \\ ${ }^{\mathrm{c}}$ Laboratory of Cellular Pharmacology and Toxicology, School of Pharmacy, Federal University of Goiás, Goiânia, Goiás, Brazil
}

\section{A R T I C L E I N F O}

\section{Article history:}

Received 5 June 2014

Accepted 24 December 2014

Available online 13 January 2015

\section{Keywords:}

In vitro cytotoxicity

Nanoparticles

\begin{abstract}
A B S T R A C T
Nanostructured drug delivery systems are based on biocompatible and biodegradable components. Composition, size and membrane surface properties are characteristics that may influence cell viability in cytotoxicity assays. In this work, four nanostructured systems commonly used for drug delivery were prepared and cytotoxicity was evaluated on human lymphocytes and Balb/c 3T3 fibroblasts. The hemolytic potential was also investigated. Polymeric nanocapsules (NC) and nanospheres (NS), nanostructured lipid carriers (NLC) and liposomes were prepared and characterized for size, distribution, zeta potential and number per volume of the colloidal dispersion. Cell viability was evaluated, 24 and $48 \mathrm{~h}$, by MTT and neutral red assays (NR). Cells were incubated with each particle in eight different dilutions varying from $2.1 \times 10^{4}$ to $2.1 \times 10^{11}$ particles/mL. Diameter of nanoparticles was between 130 and $200 \mathrm{~nm}$, all samples exhibited narrow size distribution (polydispersity index below 0.1 ) and zeta potential varied from -6.8 to $-19.5 \mathrm{mV}$. NC, NS and NLC reduced cell viability in a dilution dependent manner. For these nanoparticles, the higher number of particles induced cell death for both cell types. Liposomes did not cause loss of cell viability even at the highest number of particles. Results suggest that, depending on the kind of nanoparticle, the number of particles in the dispersion can negatively influence cell viability in pre-clinical drug development.
\end{abstract}

(c) 2015 Elsevier Ltd. All rights reserved.

\section{Introduction}

Nanoparticles engineered from a variety of organic and inorganic materials nanostructured systems currently applied in various fields, including drug and gene delivery, biosensors, cancer treatment, diagnostic tools and drug delivery (Kong et al., 2011).

The understanding of the biophysicochemical interfaces between engineered nanostructured materials and biological systems is crucial for the design of more advanced biocompatible and efficient nanodevices addressed for biological applications (Nel et al., 2009; Shang et al., 2014). Moreover, understanding the biophysicochemical interactions is very important from the perspective of safety and pre-clinical development of nanotechnology based systems for drug development and delivery.

* Corresponding authors at: Universidade Federal de Goiás, Faculdade de Farmácia, FarmaTec - 5a Avenida c/Rua 240 s/n, Praça Universitária, Goiânia, GO 74605-170, Brazil. Tel.: +55 6236096039 .

E-mail addresses: emlima@ufg.br (E.M. Lima), marizecv@ufg.br (M.C. Valadares).
The interactions between nanoparticles and biological systems including cells, tissues and organisms, is a dynamic process influenced by the properties of the nanosystem, such as, size, surface of area, shape/angle of curvature, porosity/surface crystallinity, hydrophobicity/hydrophilicity, chemical functionality, surface charge, and composition. On the other hand, the nano-biointerfaces also influenced by the composition of the biological systems (proteins, membranes, phospholipids, organelles, endocytic vesicles, DNA and biological fluids) (Verma and Stellacci, 2010).

Different types of nanostructured systems designed for drug delivery have been extensively investigated over the past decades. These include polymeric nanocapsules (NC) and nanospheres (NS), nanostructured lipid carriers (NLC) and liposomes. Thousands of papers have been published addressing performance evaluation of nanoparticulated drug delivery systems in comparison to the non-nanostructured drug. Most of these studies use cytotoxicity assays as the main tool for measuring and establishing the interaction of the nanoparticle with a biological system (Afshari et al., 2014; Cordewener et al., 2000; Kong et al., 2011). 
Cytotoxicity assays are widely used today, sometimes as the main purpose of the experiment, in preliminary investigation of the toxicity of a nanomaterial (Hillegass et al., 2010). Although several studies regarding cytotoxicity of nanomaterials are available in the literature, the vast majority is related to nonbiodegradable nanoparticles (Love et al., 2012; O'Reilly et al., 2014; Singh and Ramarao, 2012). However, most nanostructured drug delivery systems are based on biocompatible and biodegradable components. In order to obtain reliable data from cytotoxicity studies, carefully designed experiments must take into consideration not only the properties of the nanosystem, but also additional critical issues that may impact its in vitro behavior, such as the concentration of nanoparticle components, the population of the nanoparticles and structure/type of the nanoparticle (Elsaesser and Howard, 2012; Jones and Grainger, 2009). All these parameters can interfere with cellular membrane stability leading to cytotoxicity by promoting an imbalance between intra and extracellular ions, proteins and other vital molecules required to maintain normal cellular functions and properties (Love et al., 2012). Limitations of the techniques currently available and the complexity involved in assessing the toxicity of nanoparticles have also been reported (Arora et al., 2012; Jones and Grainger, 2009; Monteiro-Riviere et al., 2009; Vorup-Jensen and Peer, 2012).

In this work, four different blank nanostructured systems (NC, NS, NLC and liposomes) commonly designed for drug delivery were prepared, characterized for their main parameters (size, size distribution, zeta potential and population number) and their cytotoxicity was evaluated on two distinct cell types: human lymphocytes and Balb/c 3T3 fibroblasts. The ability of these particles in inducing hemolysis was also investigated.

\section{Material and methods}

\subsection{Preparation of nanoparticles}

Polymeric nanoparticles were prepared by the nanoprecipitation method (Mendes et al., 2014; Mora-Huertas et al., 2012). For the preparation of polymeric nanospheres (NS), the organic phase was composed of poly- $\varepsilon$-caprolactone (PCL) and sorbitan monostearate dissolved in acetone. For the nanocapsules (NC) capryc/ caprylic triglycerid was also added to the organic solution. The aqueous solution was prepared with polysorbate 80 at $0.1 \%(\mathrm{w} / \mathrm{v})$. The organic solution was poured into the aqueous solution under magnetic stirring, which was maintained for $30 \mathrm{~min}$. The organic solvent was removed under reduced pressure in a rotary evaporator (RV 10, Ika, Germany).

Nanostructured lipid carriers (NLC) were obtained by high pressure homogenization under heat (Kasongo et al., 2012; Souza et al., 2011). The lipid phase was composed of glyceril monostearate, oleic acid and sorbitan monostearate as surfactant. The lipid mixture was heated at $10^{\circ} \mathrm{C}$ above the melting point of the solid lipid and then added to the aqueous phase, containing poloxamer 188 (2.5\%). After $1 \mathrm{~min}$ in an Ultra-turrax T25 digital (Ika, Germany) for at $8000 \mathrm{rpm}$ a pre-emulsion with a volume of $200 \mathrm{~mL}$ was formed. The pre-emulsion was submitted to 6 cycles of homogenization at 500 bar in a Panda 2K (GEA Niro Soavi, Italy) to reduce particles size and cooled at room temperature to form the NLC.

Liposomes were prepared by the hydration of the thin lipid film method, followed by extrusion (Gaeti et al., 2015; Olson et al., 1979). Soy phosphatidylcholine was dissolved in chloroform and after the solvent removal by rotary evaporation a thin lipid film was formed and the flask was kept under vacuum (440/2D, Nova Ética, Brazil) for at least one hour to remove residual organic solvent. The thin-film was hydrated with ultrapure water for $1 \mathrm{~h}$, followed by 10 cycles of extrusion (Lipex ${ }^{\circledR}$ Extruder, Northern Lipids) through a $200 \mathrm{~nm}$ polycarbonate membrane.

\subsection{Nanoparticles characterization}

Nanoparticles were characterized by zeta potential ( $\zeta$-potential), $\mathrm{pH}$, particle concentration, polydispersity index (PdI) and size distribution, which was determined by two methods: dynamic light scattering (DLS) and nanoparticle tracking analysis (NTA). PdI and mean size were evaluated by DLS in a Zetasizer Nano-S (Malvern Instruments, United Kingdom), which presents the mean intensity scattered by particles in Brownian motion. NTA was accomplished in a NanoSight NS500 (Amesbury, United Kingdom) and was used to evaluate particle size and concentration in the samples. Analysis of $\mathrm{pH}$ was done directly in a digital pHmeter Orion 350 PerpHect (Thermo Scientific, USA) and zeta potential was evaluated in a ZetaPlus (Brookhaven Instruments Corporation, USA). All samples were taken directly from their original aqueous dispersion and, except for $\mathrm{pH}$ measurements, diluted (10\%) with ultrapure water for analysis. NTA measurements were performed in triplicate for each of the 5 batches characterized in the experiment and all results are expressed by the means \pm standard deviation (SD) $(n=5)$.

\subsection{Cytotoxicity assays}

Primary culture of human lymphocytes was obtained by venipuncture from healthy male donors. Equal amounts of peripheral blood and RPMI 1640 medium were mixed and layered over Histopaque $^{\circledR}-1077$ density gradient separation solution $(1.077 \mathrm{~g} / \mathrm{ml})$, which were then centrifuged for $20 \mathrm{~min}$ at $2000 \mathrm{rpm}$ and room temperature. The mononuclear cell layer (MCL) was removed, washed and resuspended in RPMI 160 medium, with $10 \%$ fetal bovine serum (FBS), antibiotics (penicillin $100 \mathrm{IU} / \mathrm{mL}$; streptomycin $100 \mu \mathrm{g} / \mathrm{mL}$ ) and $10 \mu \mathrm{g} / \mathrm{ml}$ of phytohemagglutinin. The cells were cultured for $72 \mathrm{~h}$ and after that, $90 \mu \mathrm{L}$ of the cell suspension $\left(1 \times 10^{6} \mathrm{cell} / \mathrm{ml}\right)$ was cultured in 96 -well microtiter plates, with and without each of the four types of blank nanocarriers $(10 \mu \mathrm{L})$ (NS, NC, Liposomes and NLC) for $24 \mathrm{~h}$, in different concentrations $\left(2.1 \times 10^{4}, 2.1 \times 10^{5}, 2.1 \times 10^{6}, 2.1 \times 10^{7}, 2.1 \times 10^{8}, 2.1 \times 109\right.$, $2.1 \times 10^{10}, \quad 2.1 \times 10^{11}$ particles $/ \mathrm{mL}$ ). Nanoparticle suspensions were filtered through $0.22 \mu \mathrm{m}$ Millipore PVDF filters in order to ensure sterility prior to cell culture assays.

Assessment of the cytotoxicity on human lymphocytes was performed using the 3-[4,5-dimethylthiazol-2-yl]-2,5-diphenyl tetrazolium bromide (MTT) reduction assay, adapted from Mosmann (1983). After $24 \mathrm{~h}$ of incubation $10 \mu \mathrm{L}$ of 3-[4,5-dimethylthiazol2-yl]-2,5 diphenyltetrazolium bromide (MTT) solution $(5 \mathrm{mg} / \mathrm{mL})$ was added to each well and incubated for $4 \mathrm{~h}$ in the same conditions described above. Supernatants were removed and $100 \mu \mathrm{L}$ of DMSO were added to each well to solubilize the formazan crystals. The absorbance was measured on a microplate reader at $570 \mathrm{~nm}$ in a Stat Fax 2100 Microplate Reader (Awareness Tecnologies, USA).

Balb/c 3T3 fibroblasts were cultured as a monolayer in sterile culture flasks containing DMEM supplemented with 10\% FBS. Cells were daily examined by contrast microscope. They were removed from the culture flasks using trypsinization (trypsin/EDTA solution; $0.025 \%: 0.02 \%$ ) when they reached between $50 \%$ and $80 \%$ confluence. A cell suspension containing $3 \times 10^{4}$ cells $/ \mathrm{mL}$ was prepared in DMEM supplemented with 10\% FBS and 96-well microtiter plates were seeded and incubated for $24 \mathrm{~h}$ for a monolayer with less than $50 \%$ confluence. After that period, cells were exposed to eight different concentrations of freshly prepared and diluted nanoparticles $\left(2.1 \times 10^{4}, 2.1 \times 10^{5}, 2.1 \times 10^{6}, 2.1 \times 10^{7}\right.$, $2.1 \times 10^{8}, 2.1 \times 109,2.1 \times 10^{10}, 2.1 \times 10^{11}$ particles $\left./ \mathrm{mL}\right)$ and incubated for $48 \mathrm{~h}$. Neutral red (NR) assay was performed according to the standard protocol of Borenfreund and Puerner (1985) modified by NICEATM (ICCVAM, 2006). After $48 \mathrm{~h}$ of exposure, the cells were washed and NR medium was added to all wells and incubated for 
$3 \mathrm{~h}$. The cells were briefly observed for NR crystal formation. After $3 \mathrm{~h}$, the NR medium was removed, the cells rinsed and NR desorb (50 EtOH: 1 acetic acid: 49 water) solution was added to all wells. Optical density (OD) was read at $550 \mathrm{~nm}$ in a microtiter plate reader.

\subsection{Hemolysis}

Hemolytic potential of all nanoparticles was assessed to evaluate their compatibility. Hemolysis assay was performed using 96well plates as previously described (Santos Júnior et al., 2010). Briefly, human erythrocytes were separated from serum and washed three times with saline solution containing $0.85 \%$ sodium chloride and $10 \mathrm{mM}$ calcium chloride. Erythrocytes were collected after centrifugation at $1500 \mathrm{rpm}$ for $5 \mathrm{~min}$ and a stock suspension of $2 \%(v / v)$ was prepared diluting them with the saline solution. Different concentrations of each nanoparticle were analyzed, ranging from $2 \times 10^{4}$ to $2 \times 10^{11}$ particles $/ \mathrm{mL}$. A blank of all concentrations of nanoparticles was included in the plate to null any color/turbidity interference. A negative control containing only saline solution and a positive control, containing saline solution and $0.02 \%$ Triton $\mathrm{X}-100$ were also included. Except for the blanks, every well received the stock solution of erythrocytes. The plate was incubated for two hours under agitation and centrifuged at $1500 \mathrm{rpm}$ for $10 \mathrm{~min}$. The supernatant was transferred to another plate and \% hemolysis was measured in spectrophotometer at $450 \mathrm{~nm}$.

\subsection{Nanoparticle-cell interactions}

In order to investigate the interaction of nanoparticles with lymphocytes by flow cytometry, nanoparticles were fluorescentlabeled by the addition of $2 \%$ of Egg Liss Rhod PE (L- $\alpha$-Phosphatidylethanolamine- $\mathrm{N}$-(lissaminerhodamine $\mathrm{B}$ sulfonyl)) in relation to the main structural components of each nanoparticle. Peripheral human blood was obtained by venipuncture from healthy adult donors, diluted with an equal volume of RPMI 1640 medium, then layered over Ficoll-Hypaque density gradient separation solution $(1.077 \mathrm{~g} / \mathrm{ml})$, and centrifuged at $400 \mathrm{~g}$ for $20 \mathrm{~min}$ at room temperature. The mononuclear cell layer was removed, washed twice in RPMI 1640 medium and resuspended in RPMI 1640 medium supplemented with $2 \mathrm{mM}$ glutamine (Sigma Chemical Co.), antibiotics and $10 \%$ FCS then the cells were cultured with $10 \mu \mathrm{g} / \mathrm{mL}$ of phytohemagglutinin. Lymphocytes were incubated with $2.1 \times 10^{9}$ nanoparticles for up to $6 \mathrm{~h}$. After incubation, as described above, the lymphocytes were incubated and the analysis ( 10.000 events were collected per sample) was performed with a FACS Canto II flow cytometer (Becton Dickinson, California, USA) using the FACS Diva software. In addition, the lymphocytes were directly observed in a Leica DM4000 fluorescence microscope (Wetzlar, Germany).

\subsection{Statistical analysis}

The evaluation of cytotoxicity was carried out by three separate experiments. The results were transformed in to percentages of the control. Results are expressed as the mean \pm SD of five replicates of three independent experiments. For comparison of mean values between groups. Analysis of Variance test (ANOVA) and Tukey's Multiple Comparison test were used. Statistical significance was considered when $p<0.05$.

\section{Results and discussions}

\subsection{Nanoparticles characterization and cell interactions}

Mean diameter of the nanostructured drug delivery systems ranged from 136 to $214 \mathrm{~nm}$, with a narrow size distribution as can be observed in Fig. 1. Surface area was determined as a function of the diameter, assuming that nanoparticles were spherical in shape (Mendes et al., 2014; Oliveira et al., 2012). All nanoparticle formulations exhibited a negative residual surface charge. $\zeta$ potential values were lower for liposomes (due to their phospholipid composition) and slightly higher for NS, NC and NLC.

Nanoparticle induced cytotoxicity has been recognized as a function of the physical-chemical properties of the nanoparticle, such as size, size distribution, shape and surface chemistry (Frohlich, 2012; Love et al., 2012; Verma and Stellacci, 2010). However, little or no attention has been given to the population of the nanoparticles when conducting in vitro cytotoxicity experiments. In this work, all nanoparticles evaluated were spherical in shape and with average diameters between approximately 100 and $200 \mathrm{~nm}$. Components of all nanoparticles formulations are included in the FDA inactive ingredients database under the classification of GRAS ("GRAS" is an acronym for Generally Recognized As Safe) and in equivalent amounts. Most cytotoxicity studies involving nanostructured drug delivery systems are focused on the bioactivity of the drug compound (Afshari et al., 2014; Hashem et al., 2014; Nogueira et al., 2014). However, cytotoxicity has been observed even for blank nanoparticles during the design of in vitro experiments using different cell lines (Mendes et al., 2014; Souza et al., 2011; Stecanella et al., 2013).

Determining the number of nanoparticles in a colloidal dispersion was made possible by new methods such as NTA. This technique allows visualization of particles by the light scattered when illuminated by a laser light and calculates particle size on a particle-by-particle basis. A digital camera captures videos of the light scattered by the particles and their motion is tracked from frame to frame and relate the movement to a sphere equivalent hydrodynamic radius, which also counts the number of nanoparticles in the dispersion. The nanoparticle count (in number of nanoparticles $/ \mathrm{mL}$ ) for each recently prepared formulation is shown in Fig. 1.

Incubating 3T3 cells and lymphocytes with similar concentrations (by number $/ \mathrm{mL}$ ) of liposomes, polymeric nanospheres and nanocapsules and NLC indicated that, for certain types of particles, such as soy phosphatidylcholine liposomes, even at the highest population density, no cytotoxicity signals are observed. However, a high population of blank NC, NS and CLN were able to induce cytotoxicity.

Although each nanoparticle formulation exhibited slightly different values of $\mathrm{pH}$, the final $\mathrm{pH}$ of the incubation media following the addition of the NP dispersions to the cell culture media, was maintained between 7.2 and 7.4. Furthermore, size and size distribution of the nanoparticles did not change following addition to the cell culture media.

The different types of nanoparticles (NS, NS, Liposomes, NLC) prepared with fluorescent phospholipids as a structural component were incubated with lymphocytes for three to six hours as represented in Fig. 2. Analysis of cells by flow cytometry shows the increase of fluorescence in relation to the time of incubation which represents the interactions of nanoparticles with cells. As shown in Fig. 5A, incubation of NS, NC or liposomes with lymphocytes resulted in increasing cellular internalization of nanoparticles, reaching $21 \%, 22 \%$ and 30\% respectively, after $6 \mathrm{~h}$. The higher nanoparticle-cell interaction was observed for NLC, since the increase in fluorescent cells reached 66\% in $6 \mathrm{~h}$. Photomicrographs of lymphocytes after $6 \mathrm{~h}$ of incubation with nanoparticles indicate a stronger NLC nanoparticle-cell interaction due to the higher number of fluorescence positive cells.

\subsection{Cytotoxicity assays}

In the present study the cytotoxicity of four types of blank nanocarriers (NS, NC, Liposomes and NLC), in different concentrations, 


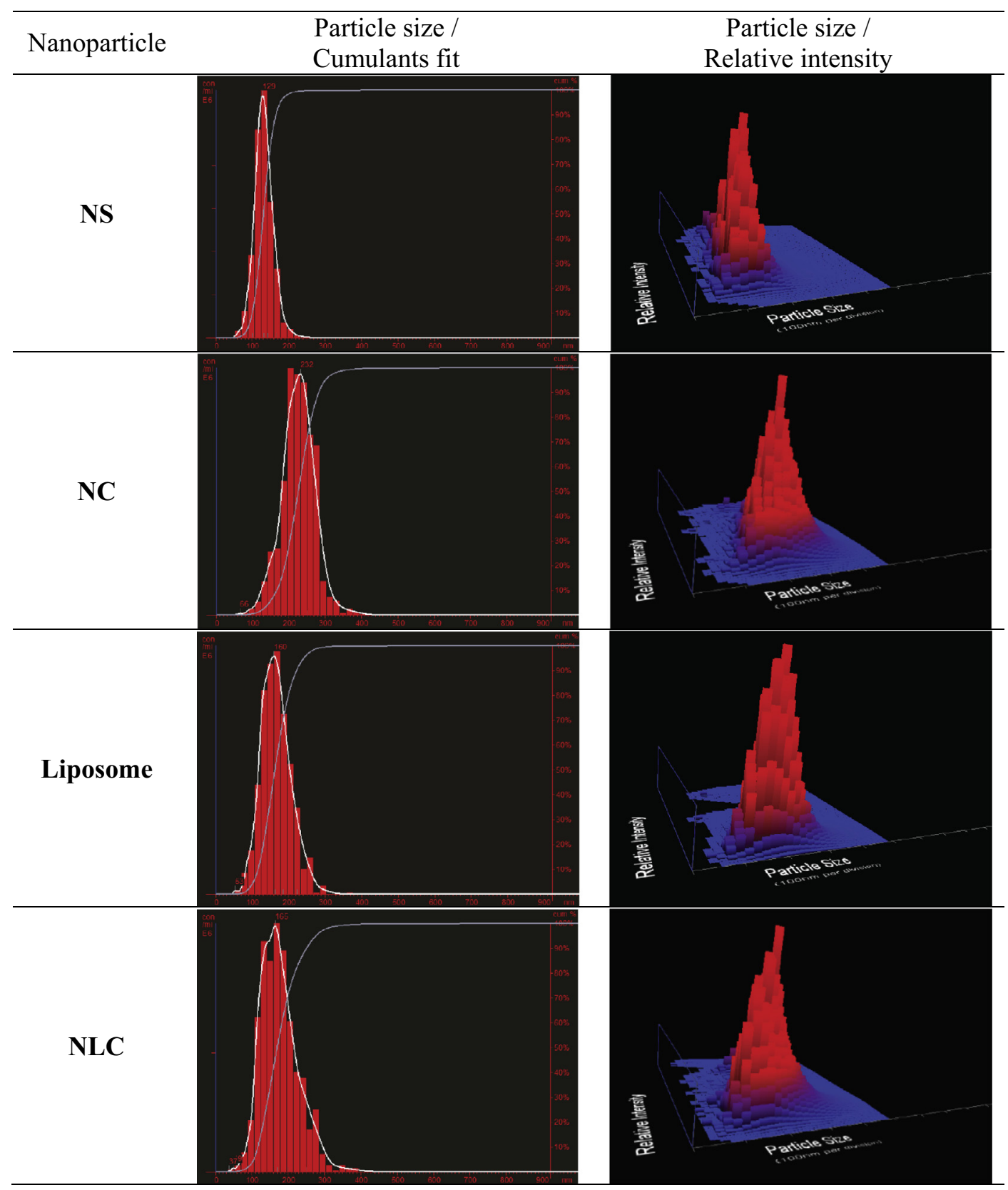

\begin{tabular}{|c|c|c|c|c|c|c|}
\hline Nanoparticle & Size $[$ d.nm] & PdI & $\begin{array}{l}\text { Initial particle } \\
\text { count }[\mathrm{NP} / \mathrm{ml}]\end{array}$ & $\begin{array}{l}\text { Surface Area } \\
{\left[\mathrm{nm}^{2} / \text { particle }\right]}\end{array}$ & $\mathrm{pH}$ & $\zeta$-Potential \\
\hline NS & $136.00 \pm 6.05$ & $0,064 \pm 0,017$ & $(6,22 \pm 0,91) \times 10^{12}$ & $58,105 \pm 2,324$ & $6.23 \pm 0.26$ & $\begin{array}{c}\text { (-) } 19.38 \pm \\
4.36\end{array}$ \\
\hline $\mathrm{NC}$ & $\begin{array}{c}214.00 \pm \\
16.09 \\
\end{array}$ & $0,118 \pm 0,0459$ & $(4,77 \pm 2,30) \times 10^{12}$ & $143,872 \pm 10,790$ & $5.78 \pm 0.94$ & $\begin{array}{l}\text { (-) } 15.02 \pm \\
4.99 \\
\end{array}$ \\
\hline Liposome & $166.17 \pm 7.35$ & $0,150 \pm 0,069$ & $(6,98 \pm 1,80) \times 10^{13}$ & $86,569 \pm 3,809$ & $4.74 \pm 0.06$ & $\begin{array}{c}\text { (-) } 6.86 \pm \\
4.01\end{array}$ \\
\hline NLC & $\begin{array}{c}195.07 \pm \\
10.76 \\
\end{array}$ & $0,180 \pm 0,062$ & $(4,96 \pm 1,95) \times 10^{12}$ & $118,236 \pm 5,911$ & $7.24 \pm 0.50$ & $\begin{array}{l}\text { (-) } 19.48 \pm \\
2.77\end{array}$ \\
\hline
\end{tabular}

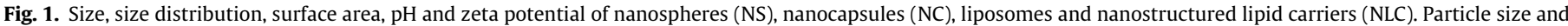

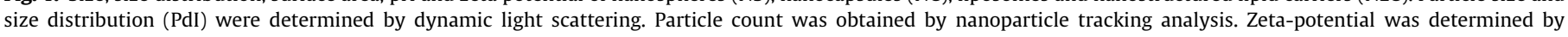

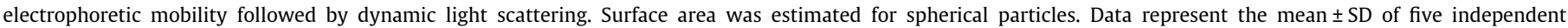
experiments. 

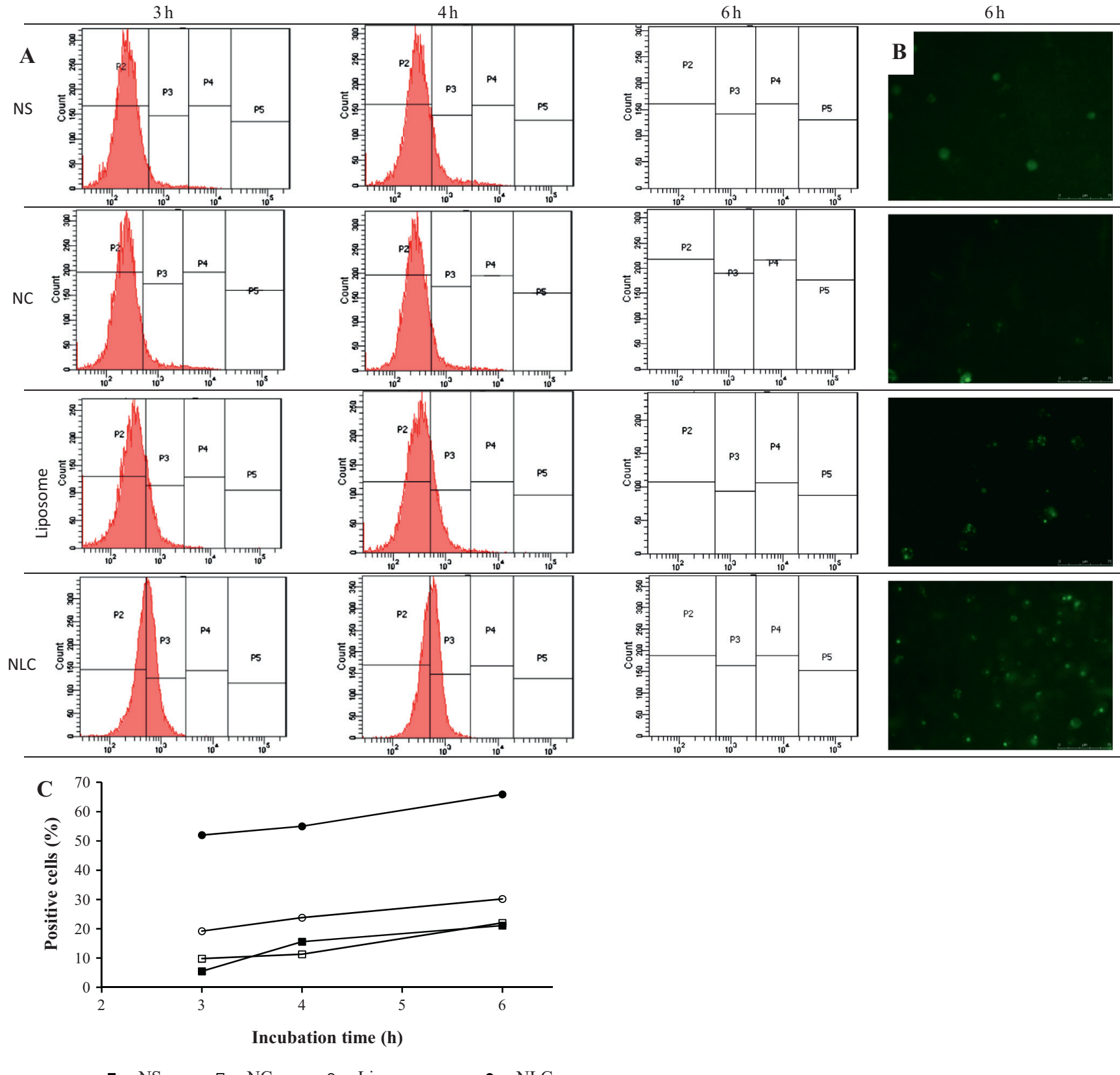

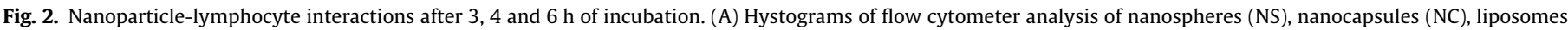

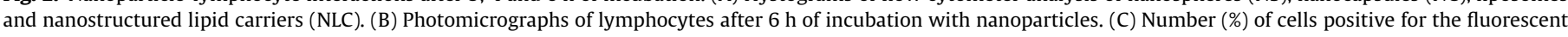
marker from nanoparticles as a function of incubation time.

calculated as number of nanoparticles per volume in each colloidal dispersion $\left(2.1 \times 10^{4}, 2.1 \times 10^{5}, 2.1 \times 10^{6}, 2.1 \times 10^{7}, 2.1 \times 10^{8}\right.$, $2.1 \times 10^{9}, 2.1 \times 10^{10}, 2.1 \times 10^{11}$ particles/mL), was investigated using human lymphocytes by the MTT reduction assay. Potential interferences of the nanoparticles with the readings of the cytotoxicity assay were ruled out by a preliminary assay, in which each nanoparticle dispersion was incubated with the MTT solution. After incubation, no changes were observed in the solution color indicating that the particles did not interact with the dye.

As represented in Fig. 3, following the incubation period of $24 \mathrm{~h}$ with the liposomal dispersion, in all concentrations studied, cell viability was not changed. However, when cells were exposed to NS or NC in the higher concentration $\left(2.1 \times 10^{11}\right.$ nanoparticles/ $\mathrm{mL}$ ) reductions of $17 \%$ and $16 \%$, respectively, on the cell viability, in comparison with non-exposed cells, were observed. Moreover, the incubation of lymphocytes with NLC at concentrations of $2.1 \times 10^{10}$ and $2.1 \times 10^{11}$ nanoparticles $/ \mathrm{mL}$ lead to a marked reduction of cell viability, reaching $55 \%$ of that of control cells.

When the blank nanocarriers (NS, NC, Liposomes and NLC), in different concentrations (number of nanoparticles/mL of the colloidal dispersion) were incubated with Balb/c 3T3-A31 and evaluated by the NRU cytotoxicity assay, following incubation for $48 \mathrm{~h}$, similar results were observed for liposomes, with no recorded cytotoxicity (Fig. 4). The NLC resulted the highest cytotoxic effects, in relation the other particles, reaching a reduction in the viability of $58 \%$ at the concentration of $2.1 \times 10^{10}$ nanoparticles $/ \mathrm{mL}$. When cells were exposed to either NLC, NS and NC at the concentration of $2.1 \times 10^{11}$ nanoparticles/mL, cell viability was reduced to 


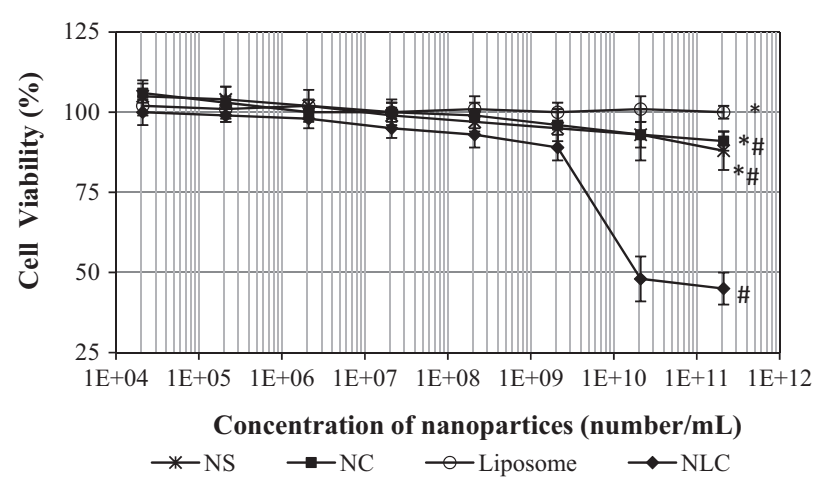

Fig. 3. Effect of nanoparticles on human lymphocyte cell viability. Cells were exposed to different concentrations (number/mL) of nanoparticles for $24 \mathrm{~h}$. At the end of incubation period MTT assay was performed to assess cell viability. Control cells were cultured in nanoparticle-free media. Cell viability was calculated as a percentage of the control group. The data are expressed as mean \pm SD of three independent experiments. $P<0.05^{*}$ in relation to NC. $P<0.05^{\#}$ in relation to liposome.

approximately $35 \%$ in relation to the control group. Blends of the individual components of each nanosystem did not interfere with cell viability under the same conditions (data not shown).

Ridolfi et al. (2011) studied the cytototoxic potential of solid lipid nanoparticles (SLN) prepared with three different lipids (cetylpalmitate, myristylmyristate and cetyl ester), by MTT assays, against Balb/c 3T3 fibroblasts or human HaCaT keratinocytes. Even though the authors were not able to determine IC50 for the nanoparticles formulations, the results demonstrated that the viability of exposed cells was significantly reduced for SLN prepared with the highest concentration of lipids tested $(500 \mu \mathrm{g} / \mathrm{mL})$.

A recent review article by Doktorovova et al. (2014) presents both supporting and conflicting data on the toxicity of SLN and NLC, pointing that neither size or composition plays a pivotal role in the toxicity exhibited by these nanoparticles, although type and amount of surfactant in the formulation might influence their cytotoxicity. Our results are in agreement with these data, in addition to providing insights on the influence of the number of nanoparticles in the dispersion on the cytotoxicity of the formulations.

Polymeric nanoparticles and solid lipid nanoparticles are not yet widely available for therapeutic uses as intravenous formulations. The number of nanoparticles in any given formulation will be a function of their structural material, as well as the encapsulated drug and encapsulation efficiency. On the other hand, liposomes have been available for therapeutic uses for approximately two decades (Chang and Yeh, 2012). In this study, liposomes did

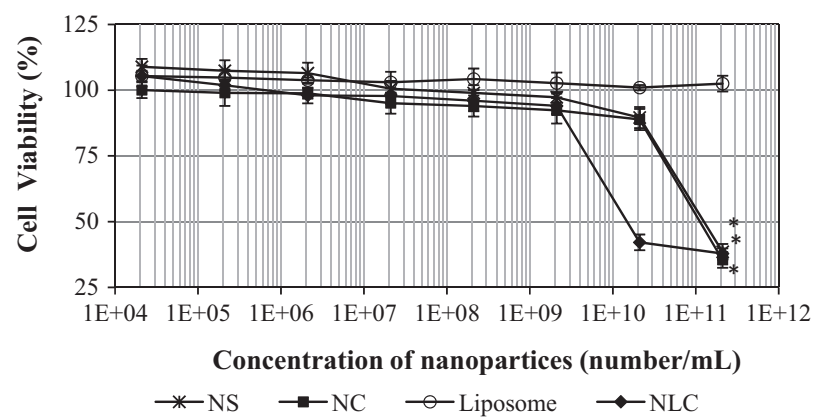

Fig. 4. Effect of nanoparticles on BALB/c 3 T3 cell viability. Cells were exposed to different concentrations (number/mL) of nanoparticles for $48 \mathrm{~h}$. At the end of incubation period Neutral Red assay was performed to assess cell viability. Control cells were cultured in nanoparticle-free media. Cell viability was calculated as a percentage of the control group. The data are expressed as mean \pm SD of three independent experiments. $P<0.05^{*}$ in relation to liposome.

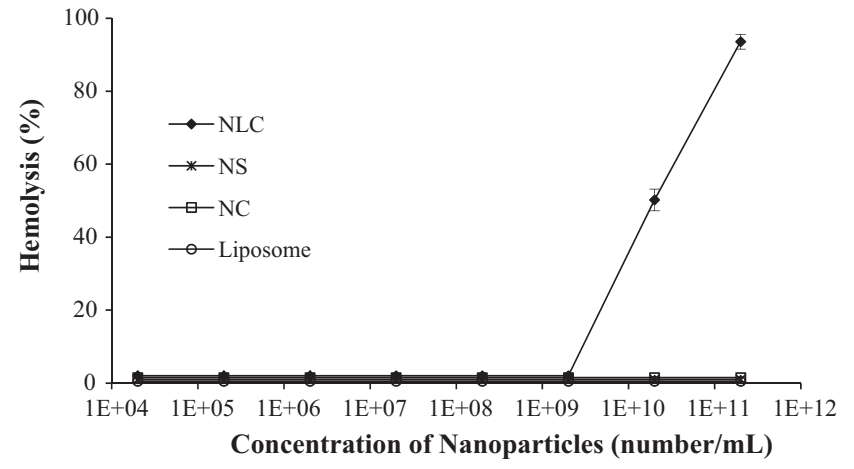

Fig. 5. Relative rate of hemolysis in human erythrocytes as a function of nanoparticles concentration (number $/ \mathrm{mL}$ ). The data are expressed as mean $\pm \mathrm{SD}$ of three independent experiments.

not exhibit any cytotoxic behavior, even at the highest number of particles per volume.

\subsection{Hemolysis}

Fig. 5 shows hemolysis from RBCs exposed to blank nanocarriers (NS, NC, Liposomes and NLC), in different concentrations (number of nanoparticles/mL of the colloidal dispersion). Hemolytic activity was only observed with NLC, while other blank nanoparticles showed less than $2 \%$ of hemolysis. NLC at $2.1 \times 10^{10}$ and $2.1 \times 10^{11}$ induced $50 \%$ and $93.5 \%$ of hemolysis, respectively. It has been noted that slight RBC alterations, such as deformability and aggregation, could result in circulatory damages to the macro and microvasculature (Kim and Shin, 2014). The hemolysis process observed in this study indicates a direct interaction between NLC and the RBC membrane, associated with the high population of the nanoparticles.

\section{Conclusions}

In this study, cytotoxicity of biodegradable nanocarriers designed for drug delivery was investigated. Nanoparticles were prepared to exhibit similar size, size distribution, shape, surface charge and main composition, however showed different cellular interaction behaviors. Changes in the population density of the nanoparticles (number $/ \mathrm{mL}$ ) resulted in cytotoxicity responses particularly for NLCs. Results suggest that, depending on the kind of nanoparticle, the number of particles in the dispersion can negatively influence cell viability in pre-clinical drug development and delivery studies. Additional studies are required to establish parameters for investigating cytotoxicity of drug delivery nanoparticles in which the number of nanoparticles in dispersion does not induce cell damage.

\section{Conflict of Interest}

The authors declare that there are no conflicts of interest.

\section{Transparency Document}

The Transparency document associated with this article can be found in the online version.

\section{Acknowledgements}

This work was supported by the Brazilian research funding agencies Conselho Nacional de Desenvolvimento Científico e Tec- 
nológico (CNPq), Financiadora de Estudos e Pesquisas (FINEP), Coordenação de Aperfeiçoamento de Pessoal de Nível Superior (CAPES), Fundação de Apoio à Pesquisa da Universidade Federal de Goiás (FUNAPE) and Fundação de Apoio à Pesquisa do Estado de Goiás (FAPEG).

\section{References}

Afshari, M., Derakhshandeh, K., Hosseinzadeh, L., 2014. Characterisation, cytotoxicity and apoptosis studies of methotrexate-loaded PLGA and PLGAPEG nanoparticles. J. Microencapsul. 31, 239-245.

Arora, S., Rajwade, J.M., Paknikar, K.M., 2012. Nanotoxicology and in vitro studies: the need of the hour. Toxicol. Appl. Pharmacol. 258, 151-165.

Borenfreund, E., Puerner, J., 1985. A simple quantitative procedure using monolayer cultures for cytotoxicity assays (HTD/NR-90). J. Tissue Culture Methods 9, 7-9.

Chang, H.-I., Yeh, M.-K., 2012. Clinical development of liposome-based drugs: formulation, characterization, and therapeutic efficacy. Int. J. Nanomed. 7, 4960.

Cordewener, F.W., van Geffen, M.F., Joziasse, C.A.P., Schmitz, J.P., Bos, R.R.M., Rozema, F.R., Pennings, A.J., 2000. Cytotoxicity of poly(96L/4D-lactide): the influence of degradation and sterilization. Biomaterials 21, 2433-2442.

Doktorovova, S., Souto, E.B., Silva, A.M., 2014. Nanotoxicology applied to solid lipid nanoparticles and nanostructured lipid carriers - a systematic review of in vitro data. Eur. J. Pharm. Biopharm. 87, 1-18.

Elsaesser, A., Howard, C.V., 2012. Toxicology of nanoparticles. Adv. Drug Deliv. Rev. 64, 129-137.

Frohlich, E., 2012. The role of surface charge in cellular uptake and cytotoxicity of medical nanoparticles. Int. J. Nanomed. 7, 5577-5591.

Gaeti, M.P.N., Benfica, P.L., Mendes, L.P., Vieira, M.S., Anjos, J.L.V., Alonso, A., Rezende, K.R., Valadares, M.C., Lima, E.M., 2015. Liposomal entrapment of 4nerolidylcatechol: impact on phospholipid dynamics, drug stability and bioactivity. J. Nanosci. Nanotechnol. 15, 838-847.

Hashem, F.M., Nasr, M., Khairy, A., 2014. In vitro cytotoxicity and bioavailability of solid lipid nanoparticles containing tamoxifen citrate. Pharm. Dev. Technol. 19, 824-832.

Hillegass, J.M., Shukla, A., Lathrop, S.A., MacPherson, M.B., Fukagawa, N.K. Mossman, B.T., 2010. Assessing nanotoxicity in cells in vitro. Wiley Interdiscip Rev. Nanomed. Nanobiotechnol. 2, 219-231.

ICCVAM, 2006. Test Method Evaluation Report (TMER): In vitro Cytotoxicity Test Methods for Estimating Starting Doses for Acute Oral Systemic Toxicity Tests. NIH publication No. 07-4519. Research Triangle Park, NC: National Institute for Environmental Health Sciences.

Jones, C.F., Grainger, D.W., 2009. In vitro assessments of nanomaterial toxicity. Adv. Drug Deliv. Rev. 61, 438-456.

Kasongo, K.W., Mueller, R.H., Walker, R.B., 2012. The use of hot and cold high pressure homogenization to enhance the loading capacity and encapsulation efficiency of nanostructured lipid carriers for the hydrophilic antiretroviral drug, didanosine for potential administration to paediatric patients. Pharm. Dev. Technol. 17, 353-362.

Kim, M.J., Shin, S., 2014. Toxic effects of silver nanoparticles and nanowires on erythrocyte rheology. Food Chem. Toxicol. 67, 80-86.
Kong, B., Seog, J.H., Graham, L.M., Lee, S.B., 2011. Experimental considerations on the cytotoxicity of nanoparticles. Nanomedicine 6, 929-941.

Love, S.A., Maurer-Jones, M.A., Thompson, J.W., Lin, Y.S., Haynes, C.L., 2012. Assessing nanoparticle toxicity. Annu. Rev. Anal. Chem. 5 (5), 181-205.

Mendes, L.P., Nogueira Gaeti, M.P., Marcelino de Avila, P.H., Vieira, M.d.S., Rodrigues, B.d.S., de Avila Marcelino, R.I., Rosa dos Santos, L.C., Valadares, M.C., Lima, E.M., 2014. Multicompartimental nanoparticles for co-encapsulation and multimoda drug delivery to tumor cells and neovasculature. Pharm. Res. 31, 1106-1119.

Monteiro-Riviere, N.A., Inman, A.O., Zhang, L.W., 2009. Limitations and relative utility of screening assays to assess engineered nanoparticle toxicity in a human cell line. Toxicol. Appl. Pharmacol. 234, 222-235.

Mora-Huertas, C.E., Garrigues, O., Fessi, H., Elaissari, A., 2012. Nanocapsules prepared via nanoprecipitation and emulsification-diffusion methods: comparative study. Eur. J. Pharm. Biopharm. 80, 235-239.

Mosmann, T., 1983. Rapid colorimetric assay for cellular growth and survival: application to proliferation and cytotoxicity assays. J. Immunol. Methods 65, 55-63.

Nel, A.E., Madler, L., Velegol, D., Xia, T., Hoek, E.M., Somasundaran, P., Klaessig, F. Castranova, V., Thompson, M., 2009. Understanding biophysicochemical interactions at the nano-bio interface. Nat. Mater. 8, 543-557.

Nogueira, D.R., del Carmen Moran, M., Mitjans, M., Perez, L., Ramos, D., de Lapuente J., Pilar Vinardell, M., 2014. Lysine-based surfactants in nanovesicle formulations: the role of cationic charge position and hydrophobicity in in vitro cytotoxicity and intracellular delivery. Nanotoxicology 8, 404-421.

Oliveira, R.R., Ferreira, S.F., Cintra, E.R., Branquinho, L.C., Bakuzis, A.F., Lima, E.M., 2012. Magnetic nanoparticles and rapamycin encapsulated into polymeric nanocarriers. J. Biomed. Nanotechnol. 8 (2), 193-201.

Olson, F., Hunt, C.A., Szoka, F.C., Vail, W.J., Papahadjopoulos, D., 1979. Preparation of liposomes of defined size distribution by extrusion through polycarbonate membranes. Biochim. Biophys. Acta 557, 9-23.

O’Reilly, L.P., Luke, C.J., Perlmutter, D.H., Silverman, G.A., Pak, S.C., 2014. C. elegans in high-throughput drug discovery. Adv. Drug Deliv. Rev. 69-70, 247-253.

Ridolfi, D.M., Marcato, P.D., Machado, D. Silva, R.A., Justo, G.Z. Durán, N., 2011. In vitro cytotoxicity assays of solid lipid nanoparticles in epithelial and dermal cells. J. Phys: Conf. Ser. 304

Santos Júnior, H., Oliveira, D., Carvalho, D., Pinto, J., Campos, V., Mourão, A., Pessoa, C. Moraes, M., Costa-Lotufo, L., 2010. Evaluation of native and exotic Brazilian plants for anticancer activity. J. Nat. Med. 64, 231-238.

Shang, L., Nienhaus, K., Nienhaus, G.U., 2014. Engineered nanoparticles interacting with cells: size matters. J. Nanobiotechnol. 12, 5.

Singh, R.P., Ramarao, P., 2012. Cellular uptake, intracellular trafficking and cytotoxicity of silver nanoparticles. Toxicol. Lett. 213, 249-259.

Souza, L.G., Silva, E.J., Martins, A.L.L., Mota, M.F., Braga, R.C., Lima, E.M., Valadares, M.C., Taveira, S.F., Marreto, R.N., 2011. Development of topotecan loaded lipid nanoparticles for chemical stabilization and prolonged release. Eur. J. Pharm. Biopharm. 79, 189-196.

Stecanella, L.A., Taveira, S.F., Marreto, R.N., Valadares, M.C. Vieira, M.d.S., Kato, M. Lima, E.M., 2013. Development and characterization of PLGA nanocapsules of grandisin isolated from Virola surinamensis: in vitro release and cytotoxicity studies. Revista Brasileira de Farmacognosia 23, 153-159.

Verma, A., Stellacci, F., 2010. Effect of surface properties on nanoparticle-cell interactions. Small 6, 12-21.

Vorup-Jensen, T., Peer, D., 2012. Nanotoxicity and the importance of being earnest. Adv. Drug Deliv. Rev. 64, 1661-1662. 